\title{
Advances through collaboration: Sharing seismic reflection data via the Antarctic Seismic Data Library System for Cooperative Research (SDLS)
}

\author{
N. Wardell, ${ }^{1}$ J. R. Childs, ${ }^{2}$ and A. K. Cooper ${ }^{3}$ \\ ${ }^{1}$ OGS (Istituto Nazionale di Oceanografia e di Geofisica Sperimentale - OGS, Borgo Grotta Gigante 42/c, 34010 Sgonico, Trieste, ITALY, \\ (nwardell@ogs.trieste.it) \\ ${ }^{2}$ U.S. Geological Survey, 345 Middlefield Road, Menlo Park, CA 94025, USA (jchilds@usgs.gov) \\ ${ }^{3}$ U.S. Geological Survey, 345 Middlefield Road, Menlo Park, CA 94025, USA (acooper@usgs.gov)
}

\begin{abstract}
The Antarctic Seismic Data Library System for Cooperative Research (SDLS) has served for the past 16 years under the auspices of the Antarctic Treaty (ATCM Recommendation XVI-12) as a role model for collaboration and equitable sharing of Antarctic multichannel seismic reflection (MCS) data for geoscience studies. During this period, collaboration in MCS studies has advanced deciphering the seismic stratigraphy and structure of Antarctica's continental margin more rapidly than previously. MCS data compilations provided the geologic framework for scientific drilling at several Antarctic locations and for high-resolution seismic and sampling studies to decipher Cenozoic depositional paleoenvironments. The SDLS successes come from cooperation of National Antarctic Programs and individual investigators in "on-time" submissions of their MCS data. Most do, but some do not. The SDLS community has an International Polar Year (IPY) goal of all overdue MCS data being sent to the SDLS by end of IPY. The community science objective is to compile all Antarctic MCS data to derive a unified seismic stratigraphy for the continental margin - a stratigraphy to be used with drilling data to derive Cenozoic circum-Antarctic paleobathymetry maps and local-to-regional scale paleoenvironmental histories.
\end{abstract}

Citation: Wardell, N, J. R. Childs, and A. K. Cooper, Advances through collaboration: Sharing seismic reflection data via the Antarctic Seismic Data Library System for Cooperative Research (SDLS), in Antarctica: A Keystone in a Changing World - Online Proceedings of the $10^{\text {th }}$ ISAES, edited by A. K. Cooper and C. R. Raymond et al., USGS Open-File Report 2007-1047, Short Research Paper 001,4 p.; doi:10.3133/of2007-1047.srp001.

\section{Introduction}

In 1991, the SDLS was designed and implemented by a consensus of participants (i.e., researchers from the countries that then collected multichannel seismic reflection (MCS) data) as an agency to promote and facilitate the use of MCS data for collaborative Antarctic geoscience research. The consensus statement and guidelines (Cooper, 1991) were adopted in 1991 by the Antarctic Treaty Consultative Parties as ATCM Recommendation XVI-12. Since then, the SDLS has been actively acquiring MCS data from data collectors and making these data openly accessible for collaborative research projects focused principally on the structure, stratigraphy and evolution of the Antarctic continental margin. More recently, the data have been used for deciphering and understanding Antarctic paleoenvironments as recorded in the characteristics of seismic data. Tabulations of MCS surveys are also now in use for delineating and monitoring seismic research studies in focus areas of known mammal activity, to ensure safe and appropriate use of seismic sources.

The SDLS differs from data banks such as the World Data Center in several significant ways that affect the way that science activities are conducted. Data banks simply provide data to researchers as requested. The SDLS is a library system that has equitable guidelines for when and how data may be accessed and used. Such guidelines, described below, have encouraged the submission and collaborative use of highly valued data in research projects. Unlike data banks that are operated by data managers, the SDLS is a data library that is under the auspices of a thematic science group SCAR-ACE (Scientific Committee on Antarctic Research - Antarctic
Climate Evolution Program) and is operated and overseen by earth scientists in 12 research organizations in 10 countries. The goal of the SDLS is both to provide data access and to promote and facilitate geoscience collaboration.

This paper provides background and current operational information on the SDLS, and gives examples of how the SDLS has been used as a successful research tool by the community to enhance collaboration in earth science projects ranging from local to circum-Antarctic scale. The paper also highlights the SDLS-IPY goal of bringing the SDLS fully up to date by further seeking the submission of all MCS data now due. All SDLS data can then be used in a major IPY project: developing a unified circum-Antarctic seismic stratigraphy for the Cenozoic.

\section{Background and current operation}

The 'heart' of the SDLS that differentiates it from a data bank, is the guideline that outlines the communityagreed timelines for data use and sharing. This guideline fairly balances the "rights" of individual data collectors to their intellectual property (i.e., their MCS data) with the "rights" of the science community to have access to the MCS data under the mandates of the Antarctic Treaty. The SDLS guideline simply states that

- within the first 4 years after data collection, data collectors have exclusive use of their MCS data; and

- from 4 to 8 years after data collection, data can only be used in collaborative studies with the data collector; and

- after 8 years from data collection, MCS data are made openly available for use, without restriction (but with due acknowledgement of the data collector). 


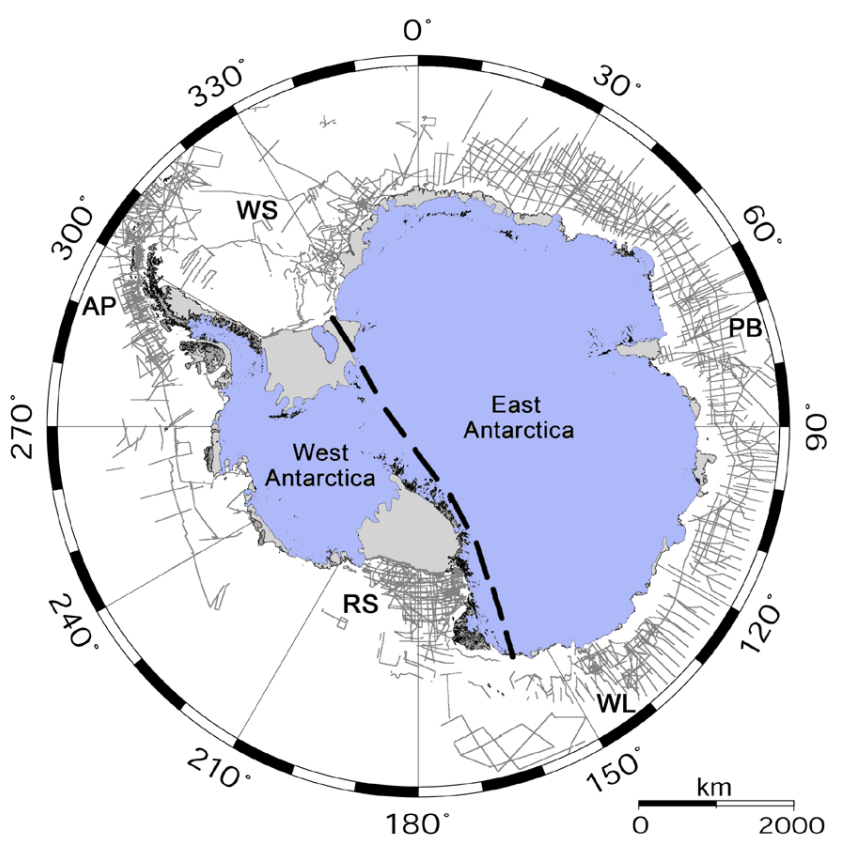

Figure 1. MCS trackline map of all MCS data, based on navigation data in the SDLS (see Plate 1). Also shown are the five regions that ANTOSTRAT working groups focused: $\mathrm{PB}=$ Prydz Bay; $\mathrm{WL}=$ Wilkes Land; RS=Ross Sea; $\mathrm{AP}=$ Antarctic Peninsula; WS=Weddell Sea.
Since 1991, over $325,000 \mathrm{~km}$ of MCS data have been collected (Figure 1) and of these, 214,400 km of MCS data have been submitted to the SDLS. The MCS data reside on either CD-ROM or DVD-ROM at each of the 12 SDLS branches world-wide. The data over 8 years from collection are also openly accessible at the principal SDLS website: http://snap.ogs.trieste.it/SDLS, where they can be viewed interactively on-line and the SEG-Y data downloaded. The site also lists all the cruises from which data have been submitted and those data that are now due at the SDLS. Currently, a secondary SDLS website: www.scar-sdls.org provides additional graphic images of the MCS data.

As a group under the ATCM, the SDLS holds workshops every 1-2 years. At the workshop, members of the geoscience community review SDLS operating procedures and discuss ways to augment and improve collaboration on current and proposed research programs. The successes of the SDLS can be traced to the workshop input and the geoscience community support. With all systems there are difficulties, and the greatest faced by the SDLS is achieving cooperation from all data collectors in submitting their data to the SDLS under the ATCM guidelines (e.g., Figure 2; data table in Plate 1). Most do, but some do not. At the last SDLS workshop (Cooper and Wardell, 2006), participants representing the MCS community set a realistic goal for IPY to achieve $100 \%$ cooperation and $100 \%$ submission of all multichannel seismic reflection data to the SDLS before the end of IPY.

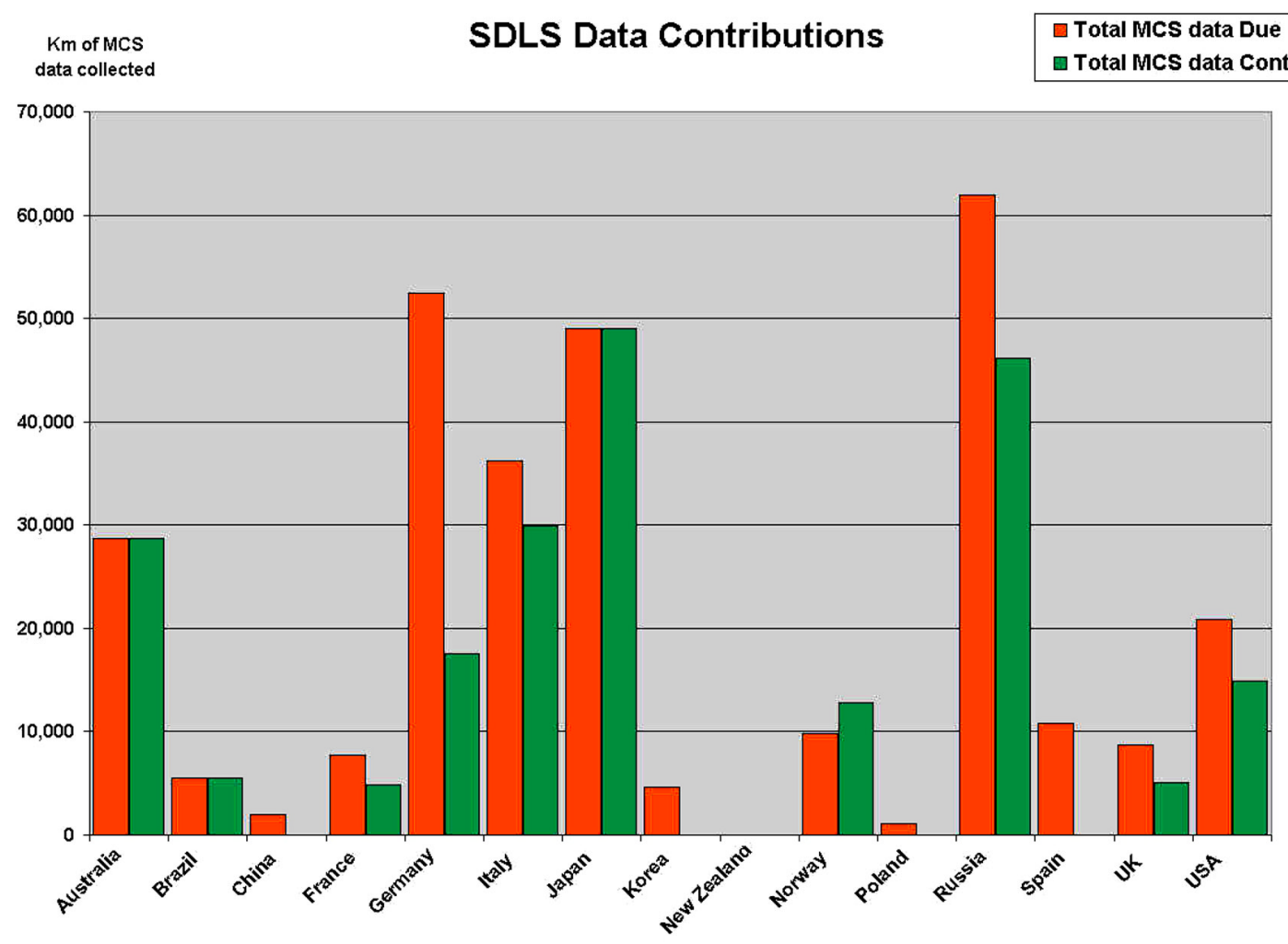

Figure 2. Chart showing the data holdings of the SDLS by country. Data due are those collected more than 4 years ago (i.e., collected before 2003). (Figure is updated from Cooper and Wardell, 2006). 
Additional information on background, policies, and data holdings for the SDLS are given in Plate 1, in the initial SDLS workshop report (Cooper, 1991, 2001), in subsequent workshop reports (Cooper and Wardell, 2006), and in science publications (e.g., Cooper and Brancolini, 1999).

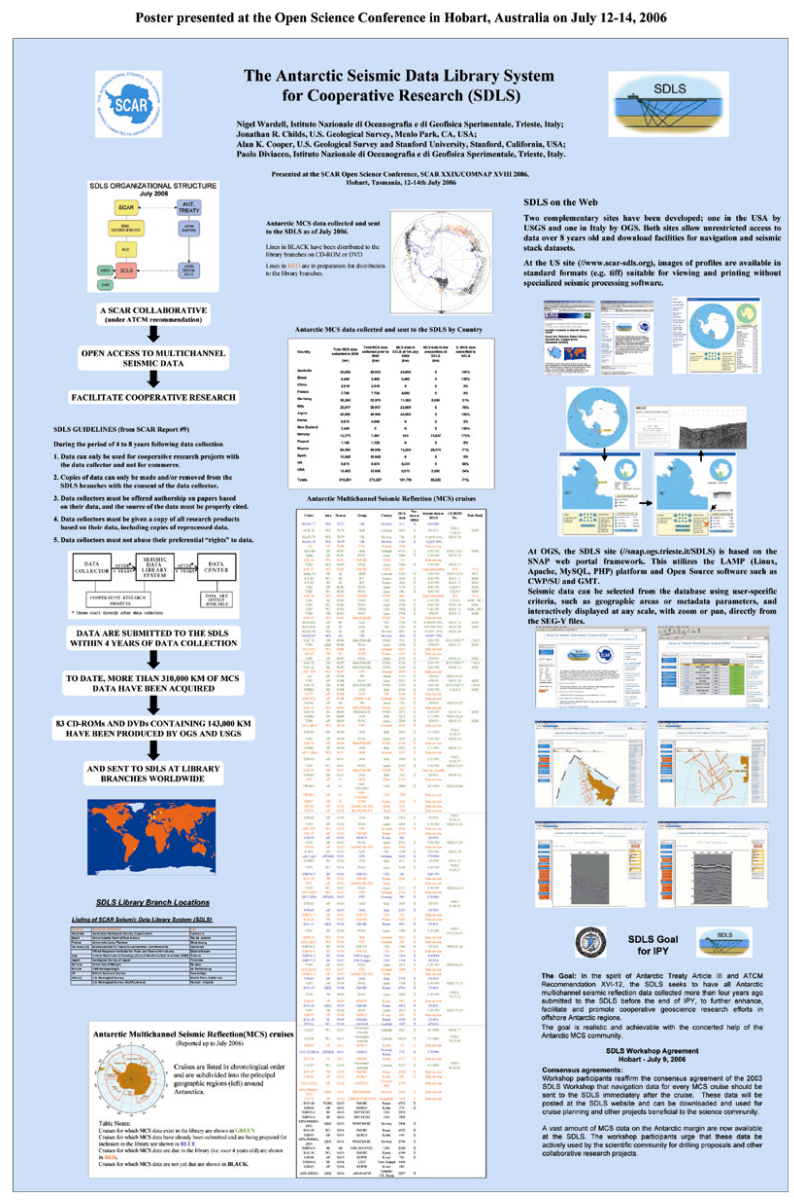

Plate 1. Poster showing organizational structure and table of Antarctic MCS data collected and in the SDLS (Wardell et al., 2006). A full-size poster image is at http://pubs.usgs.gov/of/2007/1047/papers/paper001/.

\section{Promoting and facilitating science programs}

The SDLS, when first established, provided the key data resources and incentives for science collaboration in the SCAR ANTOSTRAT (Antarctic Offshore Stratigraphy) project (Cooper and Webb, 1991). From 1989 to 2003, ANTOSTRAT working groups focused on five regions of the Antarctic margin (Figure 1), to compile and interpret geologic and geophysical data (principally seismic and drilling) to decipher structural and paleoenvironmental evolution of the continental margin. The acoustic stratigraphies derived largely from MCS data used for many of the ANTOSTRAT studies such as the Ross Sea atlas (ANTOSTRAT Project, 1995) and others were the basis for a suite of ODP drilling proposals in the five Antarctic regions (Barker et al. 1998).
Two ANTOSTRAT-led drilling proposals focused principally on Cenozoic glacial history were drilled in the Antarctic Peninsula (ODP Leg 178; Barker, Camerlenghi, Acton, 2002) and in Prydz Bay (ODP Leg 188; Cooper, O'Brien and Richter, 2004). MCS data from the SDLS were also incorporated into stratigraphic interpretations used for the Cape Robert drilling program in the McMurdo Sound region of the Ross Sea (e.g., Barrett., in press). Other drilling proposals now under the SCARACE science umbrella also incorporated SDLS-derived MCS data, and have either been drilled (e.g., ANDRILL in McMurdo Sound; ANDRILL, 2007) or are in planning stages (e.g., IODP for Wilkes Land, Ross Sea, Scotia Sea). Without the open and collaborative access to seismic data at the SDLS, such drilling programs would likely not have been possible in the time frames accomplished.

Besides facilitating and promoting Antarctic scientific drilling, the SDLS is commonly part of science planning and implementation of national and multinational marine geologic research programs to study the Antarctic continental margin. MCS data from the SDLS provide existing data to researchers to help establish regional structural framework and seismic stratigraphy for the study area. Besides ANTOSTRAT studies (e.g., ANTOSTRAT Project, 1995; Florindo and Cooper, 2001), other recent stratigraphic studies have also been facilitated by the SDLS (e.g., Soli et al., 2007; Close et al., in press). During IPY the ACE project ROSSMAP (Ross Sea Digital Geophysical and Geological Maps) will use MCS data more recently submitted to the SDLS to revise the Ross Sea stratigraphic maps in ANTOSTRAT project (1995). Additionally, a recent multinational SCAR-ACE project plans to use all existing MCS data in the SDLS and more recent data to derive a unified circum-Antarctic seismic stratigraphy (Cooper and Wardell, 2006, p.15). The stratigraphy will then be integrated with Antarctic drilling/coring samples to create a suite of paleobathymetry and paleoceanographic maps of the entire Antarctic continental margin. This project is only possible with the cooperation and collaboration of all MCS data collectors in sharing their MCS data, as implemented via the SDLS. Such unified studies are a goal of IPY, and the proposed ACE project is part of that goal.

A third science contribution of the SDLS lies in educating Antarctic geoscientists, managers and other interested groups in the proper techniques, use and interpretation of MCS data in Antarctic regions, in support of geoscience research. With the adoption of the Protocol on Environmental Protection to the Antarctic Treaty in 1991 that prohibits "any activity relating to mineral resources, other than scientific research..." (Article 7; Protocol, 1991), MCS studies now focus almost exclusively on deciphering the record of paleoenvironments and paleoclimates of the Antarctic margin. Some regional geologic MCS studies include 
Law of the Sea science objectives (e.g., Stagg et al., 2005), but the MCS data from these surveys have over the past decade filled in "holes" in data coverage that now permit us to achieve a higher scientific goal (i.e., the ACE-IPY project to compile a unified circum-Antarctic stratigraphy).

The SDLS has also helped in formulating environmental protection regimes for Antarctica, to reduce possible risks of anthropogenic noise (e.g., seismic surveys) in the marine environment. Multiple science and technical reviews by SCAR geoscience action group and information papers for the ATCM Committee for Environment Protection provide guidelines, such as minimizing the resurveying of areas, to reduce potential risks (SCAR, 2007). A long-term functioning seismic data library, created before questions on environmental sensitivities were raised, further documents that the geophysical community has acted responsibly, and is continuing to do so, in conducting seismic surveys in compliance with guidelines to protect the Antarctic marine environment.

\section{Summary}

The SDLS is a unique science support group that promotes equitable sharing of multichannel seismic reflection data for cooperative research under the science oversight of SCAR and with the geopolitical incentives of the ATCM. The 15-year history principally of success of the SDLS in facilitating collaborative Antarctic marine geoscience research is dimmed only by the slow (or no) data submissions by some groups. The SDLS seeks the complete support of the MCS community with the SDLS IPY goal of getting all overdue data into the SDLS by the end of IPY. Achieving the SDLS goal will enhance the likelihood of success for the SCAR-ACE program in attaining their goal of compiling a unified circumAntarctic seismic stratigraphy.

Acknowledgements. We thank all data collectors for their contributions to the SDLS, and Monika Breitzke for help with the trackline map compliation. We appreciate the helpful review comments from Phil O’Brien, Yngve Kristoffersen, Ray Sliter, John Behrendt, Eric Anderson, Andrés Maldonado and our co-editor, Carol Finn.

\section{References}

ANDRILL (2007), On-ice report, http://www.andrill.org/report/. ANTOSTRAT Project (1995), Seismic stratigraphic atlas of the Ross Sea, Antarctica, in Geology and Seismic Stratigraphy of the Antarctic Margin, Antarct. Res. Ser., v. 68, edited by A. K. Cooper, P. F. Barker, and G. Brancolini, 22 plates, AGU, Washington, D.C.

Barker, P. F., P. J. Barrett, A. Camerlenghi, A. K. Cooper, et al. (1998), Ice sheet history from Antarctic Continental margin sediments: the ANTOSTRAT approach, Terra Antarctica, 5(4), 737-760.
Barker, P. F., A. Camerlenghi, and G. D. Acton (eds.) (2002), Proc. ODP, Sci Results, 178 [CD-ROM]. Available from: Ocean Drilling Program: Texas A\&M University,: College Station TX 77845, USA.

Barrett, P. J. (2007), Cenozoic climate and sea level history from glacimarine strata off the Victoria Land coast, Cape Roberts Project, Antarctica, in Glacial Processes and Products, edited by M. J. Hambrey, P. Christoffersen, N. F. Glasser, and B. Hubbart, International Association of Sedimentologists Special Publication, (in press).

Close, D. I, H. M. J. Stagg, and P. E. O'Brien (2007), Seismic stratigraphy and sediment distribution on the Wilkes Land and Terre Adélie margins, East Antarctica, Marine Geology, in press.

Cooper, A. K., convener (1991-paper, 2001-web), A SCAR seismic data library system for cooperative research (SDLS): Summary report of the International Workshop on Antarctic Seismic Data, Oslo, Norway, April 11-15, 1991, SCAR Report 9,

http://www.scar.org/publications/reports/9/, with addendum 1 (2002), http://www.scar.org/publications/reports/9/addendum.html and addendum 2 (2006), http://www.scar.org/publications/reports/9/Addendum2 Report9.pdf.

Cooper, A. K. and P. N. Webb (1991), The ANTOSTRAT project International offshore studies on Antarctic Cenozoic history, glaciation, and sea-level change (Extended abstract): Abstracts of the Sixth International Antarctic Earth Science Symposium, Tokyo, Japan, September 9-13, 1991, Japan National Institute of Polar Research, p. 110-112.

Cooper, A. K. and G. Brancolini (1999), Antarctic Seismic Data Library System for Cooperative Research (SDLS), in Report of a Workshop on Antarctic Late Phanerozoic Earth System Science,

Hobart, Australia, July 6-11, 1997, compiled by P. N. Webb and A. K. Cooper, SCAR Report 16,

http://www.scar.org/publications/reports/16/appendix 7/sdls.html.

Cooper, A. K., and N. Wardell (2006), Report on the Workshop for the Antarctic Seismic Data Library System for Cooperative Research (SDLS), Hobart, Australia, July 9, 2006, SCAR Report 28, www.scar.org/publications/reports/28/Report28rev.pdf.

Cooper, A. K., P. E. O'Brien, and C. Richter, (eds.) (2004), Proc. ODP, Sci. Results, 188 [CD-ROM]. Available from: Ocean Drilling Program: Texas A\&M University: College Station, TX, 77845, USA.

Florindo, F. and A. K. Cooper (2001), Extended abstracts for the International Symposium on The geologic record of the Antarctic Ice Sheet from drilling, coring and seismic studies, Erice, Italy, September 8-14, 2001, Quaderni di Geofisica, 16, Rome, Italy, 206 p.

Protocol (1991), Protocol on Environmental Protection to the Antarctic Treaty (1991), http://www.ats.aq/uploaded/PROTOCOL.pdf

SCAR (2007), SCAR action groups on acoustics,

http://www.scar.org/researchgroups/geoscience/acoustics/

Stagg, H. M. J., J. B. Colwell, N. G. Direen, P. E. O'Brien, B. J. Brown, G. Bernadel, I. Borissova, L. Carson, and D. B. Close (2005), Geological framework of the continental margin in the region of the Australian Antarctic Territory, Geoscience Australia Record, 2004/25, $356 \mathrm{p}$.

Solli, K., B. Kuvaas, Y. Kristoffersen, G. Leitchenkov, J. Guseva, and V. Gandjukhin (2007), Seismic morphology and distribution of inferred glaciomarine deposits along the East Antarctic continental margin, $20^{\circ} \mathrm{E}-60^{\circ} \mathrm{E}$, Marine Geology, 237(3-4), 207-223.

Wardell, N., J. Childs, A. K. Cooper, and P. Diviacco (2006), The Antarctic Seismic Data Library System for Cooperative Research (SDLS), Poster presented at SCAR Open Science Conference in Hobart, Australia on July 12-24, 2006. 